Revista Brasileira de Agricultura Irrigada v.9, no .2, p. 57 - 67, 2015

ISSN 1982-7679 (On-line)

Fortaleza, CE, INOVAGRI - http://www.inovagri.org.br

DOI: $10.7127 /$ rbai.v9n200279

Protocolo 279.15 - 23/01/2015 Aprovado em 05/03/2015

\title{
AVALIAÇÃO DA OBSTRUÇ̃̃̃O DE TUBOS GOTEJADORES DEVIDO À APLICAÇÃO DE TURFA LÍQUIDA
}

Fábio Jordão Rocha ${ }^{1}$, Rubens Duarte Coelho ${ }^{2}$, Marconi Batista Teixeira ${ }^{3}$, Jorge Luis Copquer dos Santos Júnior ${ }^{4}$, Nelmício Furtado da Silva ${ }^{5}$, Fernando Nobre Cunha ${ }^{6}$

\section{RESUMO}

O objetivo desse trabalho foi avaliar a obstrução em tubos gotejadores causada pela aplicação de turfa líquida e pulso de partículas sólidas de solo em grandes quantidades. Foram utilizados dois tratamentos, sendo um composto pela aplicação de $1 \mathrm{~L}$ de turfa líquida (dosagem igual a 10 vezes a recomendada pelo fabricante para fertirrigação) diretamente na linha lateral à pressão de $150 \mathrm{kPa}$, e o outro tratamento correspondente à aplicação de $1 \mathrm{~kg}$ de solo argiloso homogeneizado em $10 \mathrm{~L}$ de água, também aplicado diretamente na linha lateral à pressão de $150 \mathrm{kPa}$. Foram utilizados quatro tipos de tubos gotejadores em cada tratamento, dispostos em dois sentidos (orifício do gotejador posicionado para cima e para baixo). Os tubos gotejadores foram inseridos em quatro níveis diferentes em um dos setores de uma Bancada de ensaios. As aplicações foram feitas individualmente para cada linha lateral durante 10 minutos. Posteriormente, determinou-se a vazão média $\left(\mathrm{q}_{\mathrm{m}}\right)$, o coeficiente de variação de vazão (CV) e a uniformidade de distribuição de água (UD). O modelo 4 apresentou baixo desempenho tanto para a aplicação de turfa líquida, quanto para a aplicação de pulso de partículas sólidas de solo na linha lateral.

Palavras-chave: entupimento, coeficiente de variação de vazão, irrigação localizada.

\section{EVALUATION OF THE DRIPLINE OBSTRUCTION BY APPLYING OF LIQUID PEAT}

\author{
ABSTRACT

\footnotetext{
${ }^{1}$ Eng. Agrônomo, Doutorando, Departamento de Engenharia Rural, Escola Superior de Agricultura Luiz de Queiroz, Universidade de São Paulo, Piracicaba, SP, C.P.: 9, CEP: 13418-900, fone (0xx19) 3447-8551, email: fjrocha@esalq.usp.br

${ }^{2}$ Eng. Agrônomo, Prof. Livre Docente, DER - ESALQ/USP, Piracicaba, SP, email: rdcoelho@esalq.usp.br

3 Eng. Agrônomo, Prof. Dr. Instituto Federal Goiano - IFGoiano - Rio Verde, GO, email: marconibt@gmail.com

${ }^{4}$ Eng. Agrônomo, Doutor, DER - ESALQ/USP, Piracicaba, SP, email: jlcdsjun@esalq.usp.br.

${ }^{5}$ Eng. Agrônomo, Doutorando em Ciências Agrárias - Agronomia. Laboratório de Hidráulica e Irrigação do Instituto Federal Goiano - IFGoiano - Rio Verde, GO, email: nelmiciofurtado@ gmail.com

${ }^{6}$ Eng. Agrônomo, Doutorando em Ciências Agrárias - Agronomia. Laboratório de Hidráulica e Irrigação do Instituto Federal Goiano - IFGoiano - Rio Verde, GO, email: fernandonobrecunha@ hotmail.com
} 
The objective of this work was to evaluate the obstruction in driplines caused by the application of liquid peat and of clay soil pulse in large amounts. Two treatments were used, one composed by the application of $1 \mathrm{~L}$ of liquid peat $(10$ times the recommended dosage for fertigation) directly on the lateral line to a pressure of $150 \mathrm{kPa}$, and the other treatment corresponds to the application of $1 \mathrm{~kg}$ of clay soil homogenized in $10 \mathrm{~L}$ of water, also applied directly in the line to a pressure of $150 \mathrm{kPa}$. Four types of driplines were used on each treatment, placed in two directions (dripper's orifice upward and downward). The driplines were inserted in four different levels in one of the sectors of a test bench. The applications were done individually for each line during ten minutes. Afterwards, the average flow was determined $\left(\mathrm{q}_{\mathrm{m}}\right)$, coefficient of variation of emitter flow (CV) and water distribution uniformity (UD). The model number 4 showed a low performance both for liquid peat application and for solid particles pulse application of soil in the line.

Keywords: clogging, coefficient of variation of emitter flow, drip irrigation.

\section{INTRODUÇÃO}

O uso de produtos orgânicos promove uma série de ações físicas, químicas e biológicas que são benéficas para as plantas e o solo. Dentre estes produtos destaca-se a turfa líquida que tem em sua composição substâncias húmicas, que são frações da matéria orgânica que podem ser consideradas como resultado das últimas transformações da matéria orgânica, que é formada por alguns ácidos como o ácido húmico; ácido fúlvico e o ácido hymatomelanico (MELO et al., 2008).

Um dos sistemas de irrigação mais apropriados e em notável expansão é o sistema de irrigação por gotejamento, que apresenta vantagens como economia de água e energia, possibilidade de automação e de fertirrigação (SOUSA et al., 2011). A turfa líquida, devido a sua grande quantidade de nutrientes é altamente indicada para o uso em fertirrigação, utilizando-se, no entanto, o sistema de irrigação por gotejamento.

Uma característica inerente ao sistema de irrigação por gotejamento é a pequena área de passagem da água nos emissores (pequenos diâmetros de orifício), o que pode ocasionar problemas de entupimento (NAKAYAMA \& BUCKS, 1991; PIZARRO CABELLO, 1996; BATISTA et al., 2006), devido a uma combinação de fatores físicos, químicos e biológicos que caracterizam a qualidade da água utilizada na irrigação que somados à prática de fertirrigação podem agravar o problem. A obstrução de emissores afeta a uniformidade de aplicação de água e, consequentemente, reduz a eficiência da aplicação de produtos químicos.

A obstrução de emissores também pode ocorrer devido à sucção de partículas de solo pelo orifício de saída de água dos gotejadores em virtude da ocorrência de vácuo (desligamento abrupto do sistema) ou rompimento de tubulações (COELHO et al., 2009).

Diversos estudos têm sido desenvolvidos com o intuito de monitorar a obstrução de tubos gotejadores e qual a melhor forma de recuperá-los, levando em conta as características hidráulicas e aspectos econômicos e ambientais (RAVINA et al., 1992; SOUZA et al., 2006; COELHO \& TEIXEIRA, 2009). Diante disso, esse trabalho teve como objetivo avaliar a obstrução em tubos gotejadores causada pela aplicação de turfa líquida e pulso de partículas sólidas de solo em grandes quantidades.

\section{MATERIAL E MÉTODOS}

O ensaio foi realizado no Laboratório de Irrigação do Departamento de Engenharia Rural, da Escola Superior de 
Agricultura "Luiz de Queiroz" ESALQ/USP, em Piracicaba-SP. Utilizouse uma Bancada em estrutura metálica, com 11 metros de comprimento. Os tubos gotejadores foram inseridos em quatro níveis diferentes de um setor da Bancada multiobjetiva, sendo dispostos em dois sentidos em cada nível (orifícios voltados para cima e orifícios voltados para baixo). Foram utilizados os modelos de tubos gotejadores Uniram $\left(1,6 \mathrm{~L} \mathrm{~h}^{-1}\right)$, DripNet $\left(1,6 \mathrm{~L} \mathrm{~h}^{-1}\right)$, DripNet $\left(0,6 \mathrm{~L} \mathrm{~h}^{-1}\right)$ e Ram $(2,3$ $\left.\mathrm{L} \mathrm{h}^{-1}\right)$, com espaçamentos entre emissores de $0,33,0,75,0,75$ e $1 \mathrm{~m}$, respectivamente. Os tubos gotejadores foram enumerados aleatoriamente para evitar especulação comercial dos dados.

A turfa líquida utilizada no ensaio corresponde a um produto comercial próprio para fertirrigação, com recomendação de $1 \mathrm{~L}$ de turfa líquida para 100 L de água. No entanto, foi utilizada uma dosagem igual a 10 vezes a recomendada, com o intuito de realizar um ensaio rápido. Utilizou-se também $1 \mathrm{~kg}$ de solo argiloso homogeneizado em $10 \mathrm{~L}$ de água. As aplicações foram feitas individualmente para cada tratamento nas linhas laterais com duração de 10 minutos.

Antes de cada aplicação dos tratamentos, aplicou-se água potável em todas as linhas laterais durante cinco horas (limpeza do sistema), sendo que a pressão utilizada durante as aplicações das soluções correspondeu a $150 \mathrm{kPa}$.

Adotou-se como um ciclo do ensaio, duas aplicações das soluções e uma leitura de vazão, repetindo-se o ciclo por duas vezes e, posteriormente foram feitas as determinações da vazão média $\left(\mathrm{q}_{\mathrm{m}}\right)$, do coeficiente de variação de vazão $(\mathrm{CV})$ e da uniformidade de distribuição de água (UD) para cada tubo gotejador ensaiado.
Selecionaram-se 10 emissores em cada linha lateral correspondente a um determinado modelo de tubo gotejador ensaiado, sendo que o procedimento para leitura individual da vazão dos gotejadores consistiu da pressurização do sistema (150 $\mathrm{kPa}$ ), posicionamento dos coletores (recipientes plásticos) sob os respectivos gotejadores com uma defasagem de 5 segundos, retirada sequencial dos coletores após cinco minutos com defasagem de 5 segundos, transporte dos coletores à bancada de pesagem, pesagem e tabulação dos dados.

Para se obter maior exatidão foi utilizado o método gravimétrico para a determinação do volume coletado de cada emissor, expressando-se os valores de vazão em $\mathrm{L} \mathrm{h}^{-1}$. Foi utilizada uma balança certificada com precisão de $0,01 \mathrm{~g}$.

Depois de tabulados os dados, foram efetuados os cálculos da vazão e de coeficiente de variação da vazão e coeficiente de distribuição de água pelos métodos mais utilizados na literatura, destacados nas equações 1 a 3 .

$$
\begin{aligned}
& q=\frac{M}{1000 t} 60 \\
& C V_{q}=\frac{s}{\bar{q}} 100 \\
& U D=\frac{q_{25 \%}}{q} 100
\end{aligned}
$$

sendo,

M - massa de água coletada, $\mathrm{g}$;

$\mathrm{t}$ - tempo de coleta, min;

$\mathrm{q}$ - vazão do gotejador, $\mathrm{L} \mathrm{h}^{-1}$;

$\mathrm{CV}_{q}$-Coeficiente de variação de vazão, \%; $s$-desvio-padrão dos dados de vazão, $\mathrm{L} \mathrm{h}^{-1}$; UD - Coeficiente de uniformidade de distribuição, \% 
$q_{25 \%}$ - média de $25 \%$ do total de gotejadores, com as menores vazões; $\mathrm{L} \mathrm{h}^{-1}$; $\bar{q}$ - vazão média, $\mathrm{L} \mathrm{h}^{-1}$.

Os dados de vazão obtidos foram submetidos à análise de variância pelo teste $\mathrm{F}$ ao nível de $5 \%$ de probabilidade, e em casos de significância, foi realizado o teste Tukey a $5 \%$ de probabilidade, utilizando-se o programa estatístico SISVAR $^{\circledR}$ (FERREIRA, 2011).

\section{RESULTADOS E DISCUSSÃO}

Na Tabela 1 está apresentada a vazão média obtida para as avaliações realizadas antes da aplicação dos tratamentos (leitura 0 ), após o primeiro ciclo (leitura 1) e após o segundo ciclo (leitura 2). Observa-se que o modelo M3 apresentou redução drástica de vazão para a leitura 2 com o orifício do gotejador voltado para cima utilizando-se a aplicação de turfa líquida, apresentando uma diferença superior a $98 \%$ dos valores obtidos para as leituras anteriores nessa mesma posição e também dos valores obtidos para o orifício do gotejador voltado para baixo, indicando uma alta suscetibilidade do M3 ao entupimento total sob aplicação de turfa líquida quando voltado para cima; similarmente, Ribeiro et al. (2010) verificaram em alguns modelos um desempenho ruim, apresentando valores de entupimento acima de $20 \%$ e chegando a $77 \%$ de redução de vazão, sendo, portanto, considerados como de alta suscetibilidade ao entupimento. Do ponto de vista prático, a vazão média de emissores pode ser considerada bom parâmetro para avaliar alterações quanto ao funcionamento adequado de emissores, seja devido a problemas de entupimento, seja a outros problemas (CARARO et al., 2006; MÉLO, 2007).

Tabela 1. Vazão média $\left(\mathrm{L} \mathrm{h}^{-1}\right)$ para a aplicação em elevadas concentrações de turfa líquida e partículas de solo argiloso diretamente na linha lateral.

\begin{tabular}{cccccc}
\hline \multirow{2}{*}{ Modelo } & & \multicolumn{4}{c}{ Vazão média $\left(\mathrm{L} \mathrm{h}^{-1}\right)$} \\
\cline { 3 - 6 } & & \multicolumn{2}{c}{ Turfa líquida } & \multicolumn{3}{c}{ Solo argiloso } \\
\cline { 3 - 6 } & Baixo & Cima & Baixo & Cima \\
\hline M1 & 0 & 2,27 & 2,14 & 2,18 & 2,12 \\
& 1 & 2,23 & 2,25 & 1,95 & 2,18 \\
& 2 & 2,26 & 2,30 & 1,93 & 2,26 \\
M2 & 0 & 1,64 & 1,63 & 1,64 & 1,67 \\
& 1 & 1,51 & 1,70 & 1,67 & 1,69 \\
& 2 & 1,77 & 1,69 & 1,68 & 1,66 \\
M3 & 0 & 1,71 & 1,72 & 1,65 & 1,66 \\
& 1 & 1,96 & 1,72 & 1,70 & 1,78 \\
& 2 & 1,75 & 0,03 & 1,39 & 2,03 \\
M4 & 0 & 0,66 & 0,63 & 0,69 & 0,63 \\
& 1 & 0,75 & 0,69 & 0,63 & 0,67 \\
& 2 & 0,71 & 0,70 & 0,81 & 0,72 \\
\hline
\end{tabular}

Para a aplicação de partículas de solo no M3 na leitura 2 com orifício do gotejador voltado para baixo, a vazão média mostrou uma diferença de 15,8 e $18,2 \%$ para a leitura 0 e 1 respectivamente. Já quanto ao orifício do gotejador voltado para cima verificou-se acréscimos de vazão conforme foi realizando a aplicação de partículas de solo da ordem de 7,2 e 22,3\%, o mesmo foi observado no M1 e M4, que mostraram aumentos de vazão de até 6,2 e $14,3 \%$, enquanto que para o M2 isto foi verificado para o orifício do gotejador voltado para baixo, entretanto com diferenças desprezíveis menores que 2,4\%. O M4 apresentou aumento de vazão para ambas as posições do emissor na linha lateral após os ciclos de aplicação de pulso de partículas sólidas de solo e de forma geral em cada leitura de vazão observou-se 
que para o modelo M1 a aplicação de partículas de solo diretamente na linha gotejadora ocasionou maiores reduções de vazão em relação à turfa líquida.

Para o modelo M4 ocorreu aumento de vazão para ambas as posições ao longo do tempo utilizando-se turfa líquida, ou seja, a elevada concentração de turfa líquida utilizada durante o ensaio ocasionou aumento de vazão, provavelmente por ter afetado o mecanismo de funcionamento da membrana de compensação de pressão desse modelo. Esses aumentos podem ser considerados como médios, sendo de 13,6\% para orifício voltado para baixo e de $11,1 \%$ voltado para cima. Essa proximidade entre as porcentagens indica que a posição pouco influenciou nesse aumento de vazão, confirmando que tal fato está mais relacionado com o funcionamento do emissor do que propriamente dito com sua posição. Logo a turfa líquida para o M4 causou distúrbios de vazão relevantes, que consequentemente irão afetar a uniformidade e eficiência de aplicação.

Ribeiro et al. (2012) trabalhando com diversos gotejadores submetidos a condições extremas de aplicação via água de irrigação, encontraram como resultado, em geral, que os gotejadores são mais suscetíveis ao entupimento quando o orifício do emissor está posicionado para baixo, juntamente com partículas em suspensão no interior dos tubos. Este resultado está em parte de acordo com os encontrados neste trabalho, pois o M1 com orifício para baixo demonstrou o melhor desempenho na aplicação de turfa líquida considerando as 3 leituras, seguido em ordem crescente de distúrbios de vazão pelo M2 (orifício para cima), M4 (orifício para cima e para baixo), M1 (orifício para cima), M2 e M3 (orifício para baixo) e M3 (orifício para cima); já quando foi realizada a aplicação de partículas de solo argiloso verificou-se a seguinte ordem: M2 (orifício para baixo e para cima), M4, M1 (orifício para cima) e M4 (orifício para baixo), M1 (orifício para baixo) e M3 (orifício para baixo e para cima).

Isto demonstra a necessidade de haver indicações mais específicas quanto à utilização dos modelos de gotejadores, pois esses não se adequam a todas as situações da mesma maneira e a sua eficiência geralmente é menor ou maior conforme o produto ou posição utilizada.

Como há pouca informação destes em condições mais adversas torna-se difícil não incorrer em erro na hora da escolha do modelo mais apropriado, já que seu comportamento pode variar de um caso para o outro.

Dutra (2010) cita que nenhum método de avaliação da qualidade da água capaz de representar o entupimento dos emissores foi desenvolvido. A causa do entupimento varia de lugar para lugar e, para a mesma água, o entupimento depende de outras condições locais, como e características construtivas dos emissores.

Para o M3 houve interação significativa entre o produto, posição e leitura, provavelmente por demonstrar uma tendência ao entupimento. A posição interferiu tanto para aplicação de partículas de solo argiloso quanto para turfa líquida apenas na última leitura, não demonstrando diferença significativa para as leituras anteriores, sendo, no entanto, a aplicação de solo inversa a da turfa no que diz respeito à posição, o que pode ser em função da diferença física e química dos produtos aplicados, o que justifica a vazão ser menor para o orifício voltado para baixo quando aplicou-se solo argiloso e a vazão menor para o orifício voltado para cima quando aplicou-se turfa líquida (Figura 1). 
A)

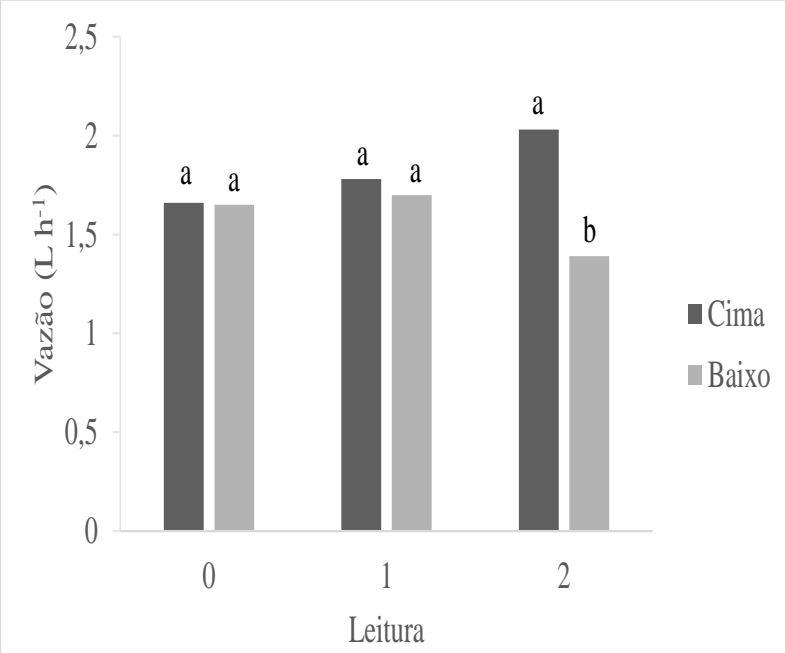

B)

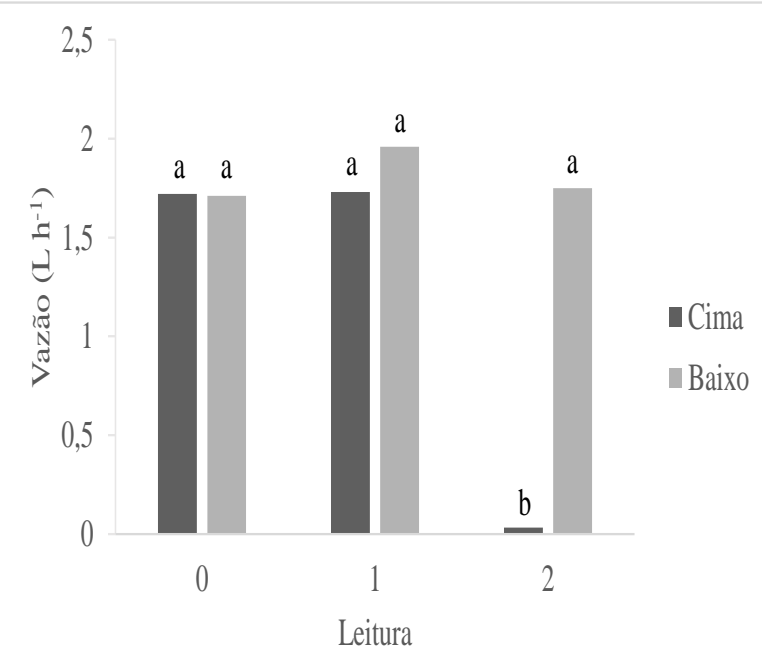

Figura 1. Vazão em função da leitura para o desdobramento da posição (orifício voltado para cima e para baixo) dentro de cada combinação de produto (solo (A) e turfa líquida (B)) e tempo para o M3.

A aplicação de solo argiloso diferiu da turfa líquida na leitura 2 para o orifício voltado para baixo, demonstrando uma diferença de aproximadamente $20,6 \%$ (solo
$<$ turfa), e quando o orifício foi voltado para cima essa diferença se mostrou extremamente grande de 98,4\% (solo > turfa) (Figura 2).
A)

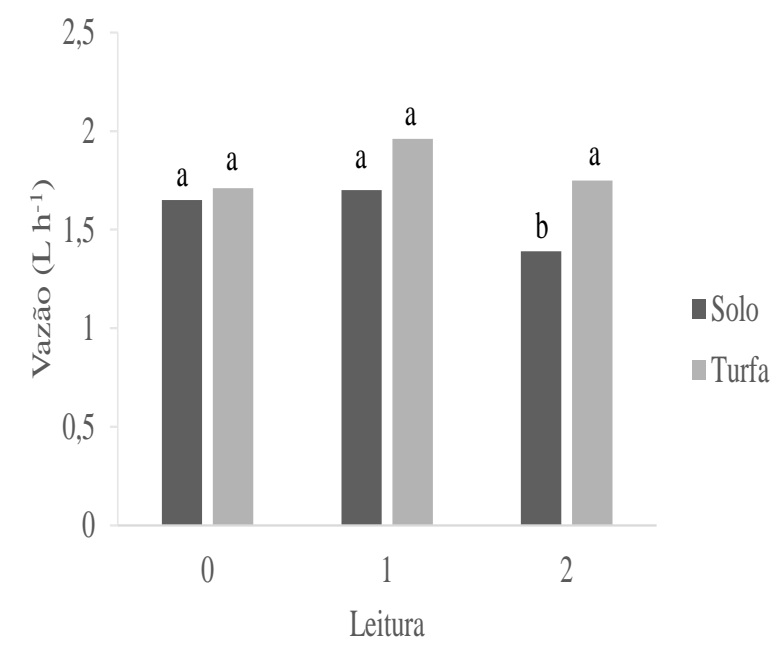

B)

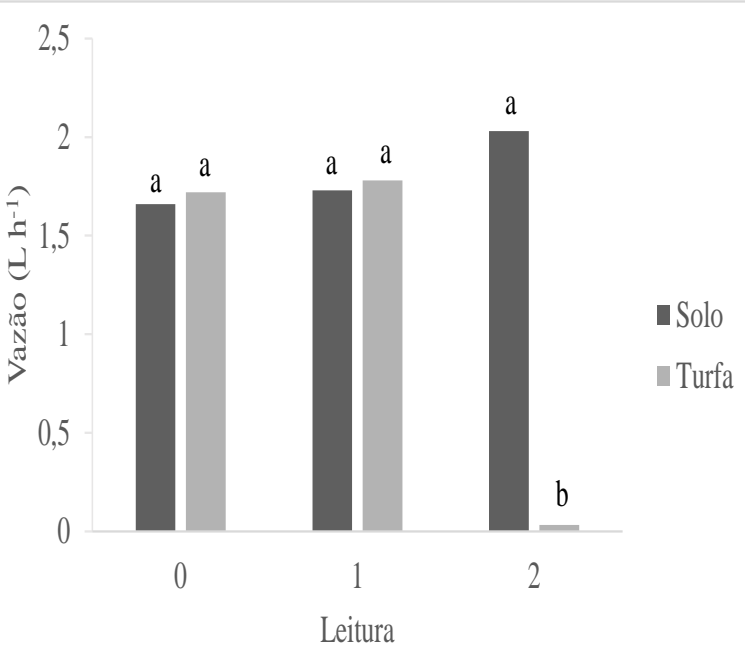

Figura 2. Vazão em função da leitura para o desdobramento do produto (solo e turfa líquida) dentro de cada combinação de posição (orifício voltado para baixo (A) e para cima (B)) e tempo para o M3.

A aplicação de turfa líquida e partículas de solo argiloso não indicou diferença entre as leituras, para o orifício voltado para baixo, entretanto para o orifício voltado para cima, com aplicação de solo argiloso, a leitura 0 foi menor
$18,2 \%$ do que a leitura 2 e igual a leitura 1 , que foi $12,3 \%$ menor do que a leitura 2 ; já sob a aplicação de turfa líquida verificou-se que a última leitura foi absolutamente menor que as leituras 0 e 1 (Figura 3). 
A)

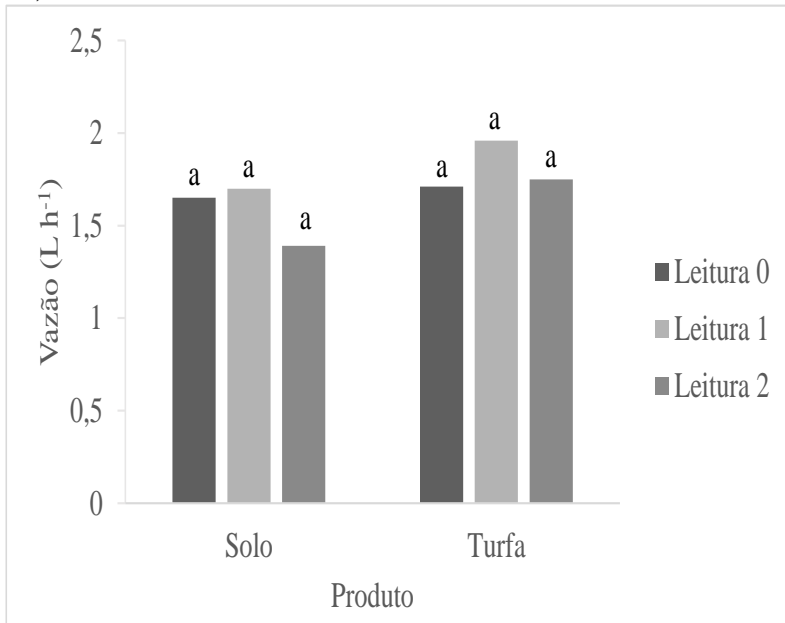

B)

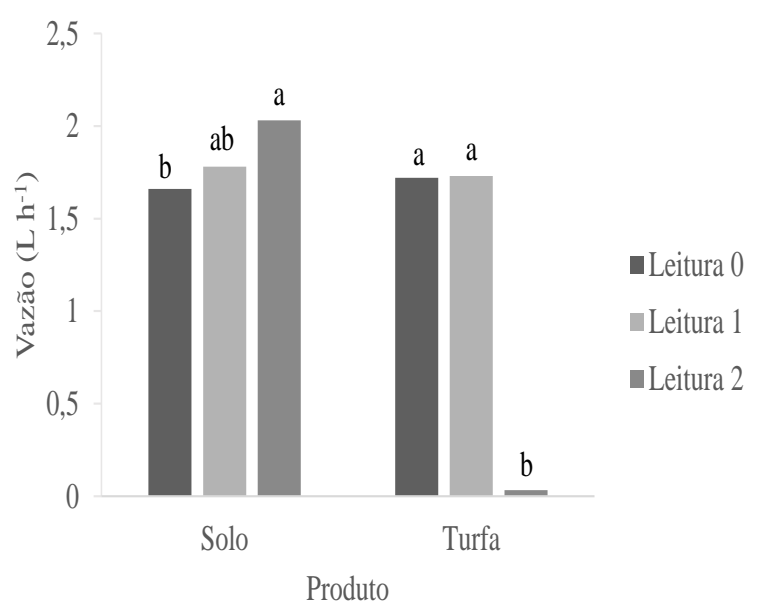

Figura 3. Vazão em função do produto para o desdobramento da leitura dentro de cada combinação de posição (orifício voltado para baixo (A) e para cima (B)) e produto (solo e turfa líquida) para o M3.

Na Tabela 2 observa-se o coeficiente de variação de vazão e a uniformidade de distribuição de água para as avaliações realizadas antes da aplicação dos tratamentos (leitura 0), após o primeiro ciclo (leitura 1) e após o segundo ciclo (leitura 2).

Tabela 2. Coeficiente de variação de vazão $(\mathrm{CV}, \%)$ e uniformidade de distribuição de água (UD, \%) para as duas fases de aplicação de turfa líquida e solo argiloso

\begin{tabular}{|c|c|c|c|c|c|c|}
\hline \multirow{2}{*}{ Modelo } & \multirow{2}{*}{ Orifício } & \multirow{2}{*}{ Avaliações } & \multicolumn{2}{|c|}{ CV (\%) } & \multicolumn{2}{|c|}{ UD (\%) } \\
\hline & & & Turfa líquida & Solo argiloso & Turfa líquida & Solo argiloso \\
\hline \multirow{6}{*}{ M1 } & \multirow{3}{*}{ P/Baixo } & 0 & 6,42 & 5,31 & 95,72 & 94,69 \\
\hline & & 1 & 7,29 & 35,72 & 92,71 & 64,28 \\
\hline & & 2 & 9,13 & 44,76 & 90,87 & 55,24 \\
\hline & \multirow{4}{*}{ P/Cima } & 0 & 7,66 & 5,45 & 92,34 & 94,55 \\
\hline & & 1 & 8,07 & 5,33 & 91,93 & 94,67 \\
\hline & & 2 & 40,62 & 6,23 & 59,38 & 93,77 \\
\hline \multirow{7}{*}{ M2 } & & 0 & 2,70 & 1,94 & 97,30 & 98,06 \\
\hline & \multirow{3}{*}{ P/Baixo } & 1 & 33,58 & 3,08 & 66,42 & 96,92 \\
\hline & & 2 & 4,90 & 3,58 & 95,10 & 96,42 \\
\hline & & 0 & 1,90 & 3,08 & 98,10 & 96,92 \\
\hline & \multirow[t]{3}{*}{ P/Cima } & 1 & 3,46 & 3,45 & 96,54 & 96,55 \\
\hline & & 2 & 2,95 & 4,20 & 97,05 & 95,80 \\
\hline & & 0 & 10,50 & 2,88 & 89,50 & 97,12 \\
\hline \multirow{5}{*}{ M3 } & \multirow[t]{3}{*}{ P/Baixo } & 1 & 28,70 & 39,93 & 71,30 & 60,07 \\
\hline & & 2 & 5,04 & 39,95 & 94,96 & 60,05 \\
\hline & & 0 & 2,68 & 2,55 & 97,32 & 97,45 \\
\hline & \multirow[t]{3}{*}{ P/Cima } & 1 & 4,00 & 4,15 & 96,00 & 95,85 \\
\hline & & 2 & 281,70 & 28,00 & - & 72,00 \\
\hline \multirow{6}{*}{ M4 } & & 0 & 4,00 & 8,28 & 96,00 & 91,72 \\
\hline & \multirow[t]{3}{*}{ P/Baixo } & 1 & 13,47 & 17,51 & 86,53 & 82,49 \\
\hline & & 2 & 39,15 & 18,77 & 60,85 & 81,23 \\
\hline & & 0 & 5,65 & 4,25 & 94,35 & 95,75 \\
\hline & \multirow[t]{2}{*}{ P/Cima } & 1 & 12,04 & 5,92 & 87,96 & 94,08 \\
\hline & & 2 & 37,27 & 16,19 & 62,73 & 83,81 \\
\hline
\end{tabular}


Em relação à aplicação de turfa líquida diretamente na linha lateral, o modelo M1 apresentou aumento de coeficiente de variação de vazão $(\mathrm{CV})$ com os emissores posicionados para cima, ou seja, o CV elevou-se de 7,66\% (antes do primeiro ciclo) para 40,62\% (após o segundo ciclo). O mesmo foi observado com aplicação de solo argiloso e orifícios voltados para baixo, mas nesse caso a variação aumentou de forma expressiva desde o primeiro ciclo, alcançando valores superiores a $44 \%$ no segundo ciclo, sendo essa variação refletida na uniformidade, que apresentou uma queda de 39\%, ocorrendo deste modo nessa leitura o menor valor de UD dentre os modelos avaliados com aplicação de partículas de solo argiloso.

O M4 ao aplicar turfa líquida apresentou aumento gradativo do CV com os emissores posicionados tanto para baixo, quanto para cima, com variações da ordem de $38 \%$, a qual demonstrou uma redução no $\mathrm{CV}$ de $50 \%$ quando foram aplicadas partículas de solo argiloso, e diferenças de UD de $21 \%$ entre a aplicação de turfa líquida e solo argiloso.

Foram observados valores de $\mathrm{CV}$ superiores a 5\%, segundo os padrões desenvolvidos pela Sociedade Americana de Engenheiros Agrícolas (ASAE) para classificação de coeficiente de variação de fabricação de tubos gotejadores (ASAE, 2003). Os valores foram observados para a leitura " 0 " correspondente aos seguintes modelos: M1 (6,42\% emissor para baixo e $7,66 \%$ emissor para cima), M3 (10,50\% emissor para baixo) e M4 (5,65\% emissor para cima). Provavelmente isso ocorreu devido ao pouco tempo de funcionamento dos tubos gotejadores antes de se iniciar os tratamentos, o que impediu a adequada ativação da regulagem da membrana de compensação desses tubos gotejadores.

O modelo M1 apresentou redução da uniformidade de distribuição de água (UD) com os emissores voltados para cima, sendo observado os valores de 92,34\% (leitura “0”), 91,93\% (leitura 1) e 59,38\% (leitura 2). O modelo M4 foi o que apresentou maior redução gradativa de UD, sendo observada uma redução superior a $30 \%$ independente da posição dos emissores quando comparada a primeira leitura em relação à última.

Com a aplicação de turfa líquida observou-se que o modelo M3 apresentou redução drástica de vazão com o orifício do gotejador posicionado para cima após o segundo ciclo, com valores inaceitáveis de coeficiente de variação de vazão $(281,70 \%)$ e valores nulos de uniformidade de distribuição de água; já com o orifício voltado para baixo, sob aplicação de turfa o comportamento do M3 foi bastante variado apresentando valores de $\mathrm{CV}$ de aproximadamente $10 \%$ na leitura 0 , aumentando essa variação na leitura 1 para $28,7 \%$ e ficando em torno de $5 \%$ na leitura 2 , o que torna muito irregular a uniformidade de aplicação; análogo a isto ocorreu com a aplicação de solo argiloso, que realçou ainda mais a fragilidade deste modelo à aplicação de ambos os produtos, pois demonstrou valores de $\mathrm{CV}$ de $40 \%$ e UD de $60 \%$ (leitura 1 e 2), consequentemente para este modelo nas duas posições dos emissores, a aplicação destes produtos ocasionou distúrbios de vazão após a leitura $0(\mathrm{CV}>28 \%)$.

O M2 foi o que apresentou o melhor comportamento frente à aplicação de pulsos de partículas sólidas de solo independente do posicionamento do orifício do gotejador, sendo observados valores de $\mathrm{CV}$ inferiores a $5 \%$, o que o classifica como excelente conforme os padrões desenvolvidos pela Sociedade Americana de Engenheiros Agrícolas (ASAE) para classificação de coeficiente de variação de fabricação de tubos gotejadores (ASAE, 2003), mas não demonstrou o mesmo desempenho quando foi aplicada turfa líquida, ainda que na leitura 0 e 2 os valores de $\mathrm{CV}$ tenham sido baixos, na leitura 1 verificou-se um 
CV acima de $33 \%$ e UD abaixo de $70 \%$, sugerindo uma propensão deste modelo a apresentar algum problema quando sob aplicação deste produto (emissores para baixo).

Gomes et al. (2013) realizaram um trabalho com o objetivo de analisar o desempenho hidráulico (variação de vazão) de 26 modelos de gotejadores autocompensantes existentes no comércio, submetidos à aplicação de turfa gel via água de irrigação, e puderam concluir que a aplicação de turfa gel na concentração de dois litros para cada 300 litros de água agravou os problemas de entupimento, mostrando que para a correta utilização desse produto via água de irrigação deve ser utilizada a concentração mínima recomendada pelo fabricante a fim de evitar alterações quanto à uniformidade de aplicação de água dos diferentes modelos de gotejadores utilizados no ensaio.

A escolha do modelo de gotejador deve levar em consideração uma série de fatores, dentre eles pode-se ressaltar que a posição e o produto a ser aplicado têm fundamental importância na escolha do modelo de gotejador. Martins (2007) ressalta que atualmente existem diversos gotejadores em uso comercial, cada tipo possui uma sensibilidade própria ao entupimento, por isso são necessários diversos critérios para a seleção dos emissores. A suscetibilidade ao entupimento caracterizase como um dos fatores que interferem nestes critérios (BATISTA, 2004).

\section{CONCLUSÕES}

O M2 foi o que apresentou o melhor comportamento frente à aplicação de pulsos de partículas sólidas de solo independente do posicionamento do orifício do gotejador (valores de $\mathrm{CV}$ inferiores a $5 \%$ );
O modelo M4 apresentou comportamento inaceitável, tanto ao final do ciclo de aplicações de turfa líquida, quanto de solo argiloso diretamente na linha lateral.

Para a utilização da turfa liquida em fertirrigação deve ser levado em consideração o modelo de tubo gotejador e principalmente a posição do orifício (voltado para baixo ou para cima), o qual alterou a uniformidade e o coeficiente de variação de todos os modelos avaliados.

\section{AGRADECIMENTOS}

Os autores agradecem ao Ministério da Ciência e Tecnologia (MCT), ao Conselho Nacional de Desenvolvimento Científico e Tecnológico (CNPq), à Fundação de Amparo à Pesquisa do Estado de São Paulo (FAPESP), à Coordenação de Aperfeiçoamento de Pessoal de Nível Superior (CAPES).

\section{REFERÊNCIAS BIBLIOGRÁFICAS}

ASAE. EP405.1: Design and installation of microirrigation systems. ASAE Standards, St. Joseph, MI, p.900-905, 2003.

BATISTA, R. O. Influência da aplicação de esgoto sanitário tratado sobre sistemas de irrigação por gotejamento. 2004. 97p. Dissertação (Mestrado em Engenharia Agrícola) - Universidade Federal de Viçosa. Viçosa, 2004.

BATISTA, R. O.; SOARES, A. A.; MATOS, A. T. de; MANTOVANI, E. C. Influência da aplicação de esgoto sanitário tratado no desempenho de um sistema de irrigação por gotejamento montado em campo. Acta Scientiarum. Technology, Maringá, v. 28, n. 2, p. 213-217, abr. jun. 2006. 
CARARO, D.C.; BOTREL, T.A.; HILLS, D.J.; LEVERENZ, H.L. Analysis of clogging in drip emitters during wastewater irrigation. Applied Engineering in Agriculture, St. Joseph, v.22, n.2, p.251-257, Mar.Apr. 2006.

COELHO, R. D.; SANTOS, J. L. C. dos; CASTIBLANCO, C. J. M.; TEIXEIRA, M. B. Suction of soil particles under vacuum conditions in subsurface drip irrigation: comparative test of emitters. ASABE Annual International Meeting, Reno, Nevada, 2009. Paper Number: 096487.

COELHO, R. D.; TEIXEIRA, M. B. Chemical damages of chlorine and acids applications on compensating drippers. ASABE Annual International Meeting, Reno, Nevada, 2009. Paper Number: 95542 .

DUTRA, A. F. A quantidade de água influencia no rendimento e na qualidade de frutos de híbrido de maracujazeiro "brs gigante amarelo". TCC. Universidade Estadual da Paraíba. Catolé do Rocha - PB, 2010, 34p.

FERREIRA, D. F. Sisvar: a computer statistical analysis system. Ciência e Agrotecnologia, Lavras, v. 35, n.6, p. 1039-1042, nov.dez. 2011.

GOMES, L. de O.; GOMES, A. W. A.; OLIVEIRA, R. C. de; TEIXEIRA, M. B.; BARROS, A. C.; COELHO, R. D. Desempenho de gotejadores em função da aplicação de turfa gel na água de irrigação. Revista Brasileira de Agricultura Irrigada. v.7, $n^{\circ} .1$, p. 27 - 41, jan. fev. 2013.

\section{MARTINS, C. C. Efeito da cloração orgânica na uniformidade de distribuição de água em sistema de irrigação por gotejamento utilizando água ferruginosa. 2007.99 p. Dissertação (Mestrado em Engenharia Agrícola) -}

Universidade Federal de Viçosa. Viçosa, 2007.

MELO, L. C. A.; SILVA, C. A; OLIVEIRA, D. B. Caracterização da matriz orgânica de resíduos de origens diversificadas. Revista Brasileira da Ciência do Solo, v.32, n.2, p.101-110, 2008.

MÉLO, R.F. Dinâmica e controle do entupimento de gotejadores em função de precipitados químicos e plâncton. 2007. 189 f. Tese (Doutorado em Irrigação e Drenagem) - Escola Superior de Agricultura "Luiz de Queiroz", Universidade de São Paulo, Piracicaba, 2007.

NAKAYAMA, F. S.; BUCKS, D. A. Water quality in drip/trickle irrigation: A review. Irrigation Science, New York, v. 12, p. 187-192, 1991.

PIZARRO CABELLO, F. Riegos localizados de alta frecuencia. 3.ed. Madrid: Mundi-Prensa, 1996. 513p.

RAVINA, I.; PAZ, E.; SOFER, Z.; MARCU, A.; SCHISCHA, A.; SAGI, G. Control of emitter clogging in drip irrigation with reclaimed wastewater. Irrigation Science, New York, v. 13, p. 129-139, 1992.

RIBEIRO, P. A. de A.; TEIXEIRA, M. B.; COELHO, R. D.; FRANCO, E. M.; SILVA, N. F. da; CARVALHO, L. C. C. de; ALVES, M. E. B. Gotejadores submetidos a condições críticas de qualidade da água. Irriga, Botucatu, Edição Especial, p. 368 - 379, 2012.

RIBEIRO, P. A. de A; COELHO, R. D.; TEIXEIRA, M. B. Entupimento de tubos gotejadores convencionais com aplicação de cloreto de potássio (branco e vermelho) via duas qualidades de água. Engenharia Agrícola, Jaboticabal, vol.30, n.2, p. 279287, mar. abr. 2010. 


\section{LÍQUIDA}

SOUSA, V. F. de; MAROUELLI, W. A.; COELHO, E. F.; PINTO, J. M.; COELHO FILHO, M. A. Irrigação e fertirrigação em fruteiras e hortaliças. Embrapa: Informação Tecnológica, Brasília, 2011, 771p.

SOUZA, J. A. A. de; CORDEIRO, E. de
A.; COSTA, E. L. da. Aplicação de hipoclorito de sódio para recuperação de gotejadores entupidos em irrigação com água ferruginosa. Revista Brasileira de Engenharia Agrícola e Ambiental, Campina Grande, v.10, n.1, p.5-9, mar. 2006. 